\title{
Jurist-Diction
}

Volume 4 No. 1, Januari 2021

\section{Pemblokiran Penunjukkan Anggota Appellate Body Berkenaan Dengan Pemenuhan Right To Access To Justice Dalam World Trade Organization}

\author{
Novia Dwi Lestari \\ noviadwlestari@gmail.com \\ Universitas Airlangga
}

\begin{abstract}
How to cite:
Novia Dwi Lestari,

'Pemblokiran Penunjukkan

Anggota Appellate Body

Berkenaan Dengan

Pemenuhan Right To Access

To Justice Dalam World Trade

Organization' (2021) Vol. 4

No. 1 Jurist-Diction.

Histori artikel:

Submit 1 Oktober 2020;

Diterima 12 November 2020;

Diterbitkan 5 Januari 2021.

DOI:

10.20473/jd.v4i1.24301

p-ISSN: 2721-8392

e-ISSN: 2655-8297
\end{abstract}

\begin{abstract}
The World Trade Organization (WTO) dispute settlement system become pivotal when it comes to the right to access to justice in international trade. As a part of the WTO dispute settlement system, the $A B$ takes a role in providing the right to access to justice for the WTO Members. The AB existence has guaranteed and strengthened consistency and certainty of interpretation of international trade law. However, the role of AB is threatened by the United States (US). Since 2017, the US has been blocking the process for appointment and re-appointment of $A B$ Members. By 11 December 2019, the AB was unable to review appeals because of the lack of quorum for the division. Based on the procedural aspect, dispute settlement institution must function to fulfill the right to access justice. The US blocking has aimed the fulfillment of the right to access to justice of the WTO Members.

Keywords: Dispute Settlement System; World Trade Organization; Appellate Body; Right to Access to Justice; Blocking.
\end{abstract}

\begin{abstract}
Abstrak
Sistem penyelesaian sengketa World Trade Organization (WTO) menjadi sangat penting jika menyangkut right to access to justice dalam perdagangan internasional. Sebagai bagian dari sistem penyelesaian sengketa WTO, Appellate Body (AB) turut berperan dalam pemenuhan right to access to justice bagi negara-negara anggota WTO. Keberadaan AB telah menjamin dan memperkuat konsistensi serta kepastian terhadap penafsiran aturan perdagangan internasional. Namun, peran AB tersebut terancam karena Amerika Serikat. Sejak tahun 2017, Amerika Serikat telah memblokir proses penunjukkan dan penunjukkan kembali anggota AB. Per 11 Desember 2019, AB tidak dapat melakukan peninjauan banding karena kurangnya kuorum divisi. Berdasarkan aspek prosedural, institusi penyelesaian sengketa harus dapat berfungsi agar mampu memenuhi right to access to justice. Pemblokiran yang dilakukan oleh Amerika Serikat telah menciderai pemenuhan right to access to justice negara-negara anggota WTO.

Kata Kunci: Sistem Penyelesaian Sengketa; World Trade Organization; Appellate Body; Right to Access to Justice; Pemblokiran.
\end{abstract}

Copyright (C) 2021 Universitas Airlangga 


\section{Pendahuluan}

Salah satu karakteristik penting dalam penyelesaian sengketa era GATT adalah aturan positive consensus. Aturan tersebut mewajibkan adanya konsensus dari seluruh pihak (the GATT Contracting Parties) dalam proses pengambilan keputusan. Hal ini berarti bahwa pihak yang kalah dalam sengketa tidak hanya dapat menolak untuk setuju dan memblokir adopsi terhadap laporan panel, tetapi juga dapat menolak pembentukan panel di awal. ${ }^{1}$ Pemblokiran terhadap proses adopsi laporan panel maupun penolakan terhadap pembentukan panel di awal berdampak pada tidak dapat diselesaikannya sengketa perdagangan melalui sistem GATT. Untuk menghindari kemungkinan buruk yang timbul karena aturan positive consensus tersebut, maka pada era WTO aturan tersebut diganti menjadinegative atau reverse consensus. Berdasarkan bentuk konsensus tersebut, laporan secara otomatis diadopsi, kecuali terdapat konsensus untuk tidak mengadopsi laporan tersebut. ${ }^{2}$ Dengan demikian negara yang kalah dalam sengketa tidak lagi dapat memblokir proses adopsi laporan. Pengambilan keputusan dalam sistem penyelesaian sengketa WTO diserahkan pada Dispute Settlement Body (DSB). Legitimasi DSB tergantung pada pengakuan negara-negara anggota WTO sebagai 'guarantor body of the right to access to justice'. ${ }^{3}$

Keberadaan sistem penyelesaian sengketa berkaitan erat dengan pemenuhan right to access to justice. Secara sederhana, istilah right to access to justice dapat dipahami sebagai hak akses untuk menyelesaikan sengketa. Dalam WTO, aksesbilitas terhadap sistem penyelesaian sengketa tercantum dalam Article 1 para. 1 DSU yakni bahwa hanya negara anggota WTO yang mempunyai akses dan hanya terhadap sengketa yang timbul di bawah perjanjian-perjanjian WTO. ${ }^{4}$

1 David Palmeter dan Petros C. Mavroidis, Dispute Settlement in the World Trade Organization: Practice and Procedure (Springer Science+Business Media Dordrecht 1999).[9]-[10].

2 Koesrianti, 'WTO Dispute Settlement Mechanism: Indonesia's Prospective in International Trading System’ (2015) 27 Mimbar Hukum.[306].

3 Inez Lopes, 'Dispute Settlement Body of The WTO: Access to Developing Countries?' (2014). 1 Journal of the Graduate Program in Law of University of Brasilia.[54].

4 Annex 2 Marrakesh Agreement Establishing the World Trade Organization 1994 Understanding on Rules and Procedures Governing the Settlement of Disputes (selanjutnya disingkat DSU). 
Sistem penyelesaian sengketa WTO semakin diperkuat dengan pembentukan Appellate Body (Selanjutnya disebut AB). Badan banding tersebut terdiri dari 7 orang anggota yang ditunjuk oleh DSB untuk masa kerja selama 4 tahun dan dapat ditunjuk kembali. ${ }^{5}$ Pengambilan keputusan oleh DSB dalam proses penunjukkan dan penunjukkan kembali anggota $\mathrm{AB}$ berpedoman pada ketentuan dalam Article 2 para. 4 DSU yaitu dengan menggunakan aturan positive consensus. Dengan demikian, negara-negara anggota WTO memiliki kesempatan untuk dapat menolak mendukung proses tersebut.

Selama beberapa tahun terakhir, Amerika Serikat telah melakukan pemblokiran terhadap proses penunjukkan dan penunjukkan kembali anggota $\mathrm{AB}$. Amerika Serikat melalui US International Trade Commission (USTR) menyatakan akan terus melakukan pemblokiran sampai isu yang dipermasalahkan diatasi. ${ }^{6}$ Sejak tahun 2017, jumlah anggota $A B$ terus berkurang. Mulai 1 Oktober 2018, setiap laporan panel yang diajukan banding $\mathrm{ke} A B$ harus ditangani oleh tiga anggota $\mathrm{AB}$ yang sama. Setelah 10 Desember 2019, AB hanya memiliki satu anggota. Dalam ketentuan DSU, setiap peninjauan banding harus ditangani oleh tiga anggota $\mathrm{AB} .^{7}$ Kondisi $\mathrm{AB}$ yang hanya memiliki satu anggota tidak memenuhi syarat kuorum tersebut, sehingga $\mathrm{AB}$ tidak dapat melakukan peninjauan banding.

Situasi yang terjadi pada $\mathrm{AB}$ mengkhawatirkan bagi negara-negara anggota WTO, khususnya negara berkembang (developing dan least-developed countries), yang bergantung pada temuan dan rekomendasi $\mathrm{AB}$ untuk memiliki legitimasi guna membahas ketentuan pelaksanaan dengan negara anggota WTO yang melanggar. ${ }^{8}$ Tindakan pemblokiran oleh Amerika Serikat yang berujung pada kelumpuhan $\mathrm{AB}$ telah mengganggu upaya penegakan dan pemenuhan hak-hak negara-negara anggota WTO, khususnya right to access to justice.

5 Pasal 17 ayat (1) dan (2) DSU.

6 United State International Trade Commission (USTR), 'Statement by Ambassador Robert E. Lighthizer on Retaliatory Duties' (Press Release, 26 Juni 2018) <https://ustr.gov/about-us/ policy-offices/press-office/press-releases/2018/june/statement-ambassador-robert-e $>$ accessed 26 Januari 2020.

7 Pasal 17 ayat (1) DSU

8 Alberto do Amaral Junior, Luciana Maria de Oliveira Sa Pires, dan Cristiane Lucena Carneiro (eds), The WTO Dispute Settlement Mechanism: A Developing Country Perspective, (Springer Nature Switzerland 2019).[5]. 


\section{Metode Penelitian}

Penelitian ini merupakan penelitian hukum dengan menggunakan metode pendekatan peraturan perundang-undangan (statute approach) dan pendekatan konseptual (conseptual approach). Pendekatan peraturan perundang-undangan dilakukan dengan menelaah semua undang-undang dan regulasi yang bersangkut paut dengan isu hukum yang sedang ditangani. ${ }^{9}$ Pendekatan konseptual dilakukan dengan mempelajari pandangan dan doktrin-doktrin yang telah ada dalam ilmu hukum. ${ }^{10}$

\section{Kedudukan Appellate Body dalam Sistem Penyelesaian Sengketa WTO}

Keberadaan $\mathrm{AB}$ sebagai mekanisme banding telah menciptakan perubahan terhadap cara kerja sistem ajudikasi dalam WTO. Konsistensi dan kepastian terhadap penafsiran aturan perdagangan internasional juga dijamin dan diperkuat oleh AB. Tidak salah jika AB mendapat sebutan sebagai 'centerpiece' sistem penyelesaian sengketa WTO. Pada saat pembentukannya, AB diharapkan dapat menjadi 'a security blanket' atau 'a safety valve' untuk melawan putusan Panel yang buruk atau keliru. ${ }^{11}$

Ketentuan mengenai prosedur penyelesaian sengketa banding AB secara khusus diatur dalam Article 17 DSU dan lebih lanjut dalam Working Procedures. Orang yang ditunjuk untuk menjadi anggota $\mathrm{AB}$ haruslah memenuhi kualifikasi yang diatur dalam Article 17 para. 3 DSU. Hak akses terhadap peninjauan banding dalam $\mathrm{AB}$ sangatlah terbatas. Hanya pihak-pihak dalam sengketa (the complainant dan the respondent) yang memiliki 'automatic right to appeal'. ${ }^{12}$ Peninjauan banding hanya terbatas pada isu hukum dan interpretasi hukum dalam laporan panel. ${ }^{13}$ Proses peninjauan banding terhadap masing-masing laporan

\footnotetext{
9 Peter Mahmud Marzuki, Penelitian Hukum (Cetakan VI Kencana 2010).[32].

10 ibid.[95].

${ }^{11}$ Debra P. Steger, 'The Appellate Body and its contribution to WTO Dispute Settlement', dalam D. L. M. Kennedy \& J. D. Southwick (ed), The Political Economy of International Trade Law: Essays in Honor of Robert E. Hudec (Cambridge University Press 2002). [483].

${ }_{12}$ Pasal 16 ayat (4) dan Pasal 17 ayat (4) DSU.

13 Pasal 17 ayat (6) DSU.
} 
panel yang diajukan banding dilakukan oleh 3 orang anggota $\mathrm{AB}$ yang disebut sebagai division. ${ }^{14}$ Proses peninjauan banding $\mathrm{AB}$ memiliki batas waktu yang ketat yakni tidak boleh melebihi batas waktu 90 hari. ${ }^{15}$ Laporan AB yang telah diedarkan harus diadopsi oleh DSB dan diterima tanpa syarat oleh para pihak dalam sengketa. ${ }^{16}$ Laporan $\mathrm{AB}$ yang telah diadopsi bersifat final dan binding (mengikat para pihak dalam sengketa). Kekuatan mengikat tersebut menjadi salah satu karakteristik penting yang menunjukkan pentingnya kedudukan AB dalam sistem penyelesaian sengketa WTO.

\section{Konsep Right to Access to Justice}

Ketika suatu hak dilanggar, access to justice menjadi hal penting yang mendasar bagi individu yang dilanggar haknya dan merupakan komponen penting dalam sistem perlindungan dan penegakkan hak asasi manusia. ${ }^{17}$ Istilah right access to justice merupakan gagasan yang lahir dari hak-hak dasar (fundamental rights) yang kemudian diakui dalam standar internasional sebagai basic human right. Dari perspektif hukum, kata 'access' dalam access to justice berkaitan dengan kedudukan hukum (legal standing) untuk mengajukan penyelesaian sengketa. ${ }^{18}$ Lebih lanjut, konsepnya dapat dipahami sebagai cara untuk memastikan proses hukum dan hasilnya dapat adil dan merata.

Dalam berbagai instrumen hukum internasional penyebutan right to access to justice menggunakan terminologi yang berbeda-beda. Dalam Article 8 Universal Declaration of Human Rights (UDHR) terminologi yang digunakan adalah 'right to an effective remedy'. Terminologi 'effective remedy' dan 'access to justice' sering digunakan secara bergantian untuk melindungi:

14 Pasal 17 ayat (1) DSU, Working Procedures for Appellate Review, WT/AB/WP/6, 16 Agustus 2010 [Rule 1].

${ }^{15}$ Pasal 17 ayat (5) DSU.

${ }_{16}$ Pasal 17 ayat (14) DSU.

17 Francesco Francioni, 'The Rights of Access to Justice under Customary International Law', dalam Francesco Francioni (ed), Access to Justice as a Human Right (Oxford University Press 2007).[1].

${ }_{18}$ Robert O. Keohane, Andrew Moravesik, dan Anne-Marie Slaughter, 'Legalized Dispute Resolution: Interstate and Transnational' (2000) 54 International Organization.[462]. 
1. Hak individu untuk akses ke badan penyelesaian sengketa;

2. Hak untuk proses hukum yang adil;

3. Hak untuk menyelesaikan sengketa tepat waktu;

4. Hak untuk mendapat ganti rugi yang memadai; dan

5. Prinsip efisiensi dan efektivitas dalam pemulihan hukum. ${ }^{19}$

Konsep access to justice sangatlah interpretatif dan kontekstual, sehingga memiliki berbagai makna dan pemahaman. Menurut Cappelletti dan Garth yang berfokus pada tujuan sistem hukum:

"The words "access to justice" are admittedly not easily defined, but they serve to focus on two basic purposes of the legal system-the system by which people may vindicate their rights and/or resolve their dispute under the general auspices of the state. First, the system must be equally accessible to all; second, it must lead to results that are individually and socially just", ${ }^{20}$

Sederhananya access to justice berarti bahwa memudahkan setiap orang untuk menggunakan sistem hukum atau membuat sistem hukum menjadi lebih mudah diakses (accessible). Menurut Robert H. Bork, access to justice adalah akses pada pengadilan berkompeten yang memiliki jangka waktu untuk memberikan pertimbangan yang matang terhadap masalah hukum, dapat menyampaikan keputusan yang adil dalam waktu yang wajar, dan dapat menjelaskan alasan dari keputusan tersebut. ${ }^{21}$

Dalam konsep right to access to justice terkandung dua aspek yakni aspek substantif dan prosedural. Aspek substantif memiliki arti 'getting justice', sedangkan aspek prosedural berarti 'the process of getting justice'. ${ }^{22}$ Aspek prosedural berfokus pada peluang dan hambatan untuk mengajukan klaim ke pengadilan

${ }^{19}$ Ernst-Ulrich Petersmann, 'Judicial Standards of Review and Administration of Justice in Trade and Investment Law and Adjudication', dalam Lukasz Gruszczynski dan Wouter Werner (ed), Deference in International Courts and Tribunals: Standard of Review and Margin of Appreciation (Oxford University Press 2014).[23].

20 Mauro Cappelletti dan Bryant G. Garth, 'Access to Justice: The Newest Wave in the Worldwide Movement to Make Rights Effective’ (1978) 27 Buffalo Law Review.[182].

${ }^{21}$ United States Committee on the Judiciary Subcommittee on Courts, Civil Liberties, and the Administration of Justice, State of the Judiciary and Access to Justice Hearings before the Subcommittee on Courts, Civil Liberties, and the Administration of Justice of the Committee on the Judiciary House of Representatives Ninety-Fifth Congress (U.S. Government Printing Office 1977). [242].

${ }^{22}$ Miao He, 'Sustainable Development through the Right to Access to Justice in Environmental Matters in China’ (2019) MDPI Journal.[1]-[2]. 
atau forum penyelesaian sengketa lainnya. ${ }^{23}$ Dalam pendekatan yang lebih luas, aspek prosedural menyangkut jenis institusi hukum yang dapat digunakan untuk mengajukan klaim, aturan yang mengatur proses penyelesaian masalah hukum, dan mandat tertentu yang diberikan kepada institusi hukum yang akan menyelesaikan permasalahan hukum. ${ }^{24}$ Aspek substantif dari rights to access to justice berkaitan dengan penilaian klaim hak yang tersedia. ${ }^{25}$ Aspek tersebut berfokus pada adil tidaknya solusi yang dihasilkan dari proses penyelesaian permasalahan hukum.

Dalam hukum internasional, Negara merupakan subyek hukum yang pertama dan paling utama. Hal ini berarti bahwa negara mengontrol akses terhadap penyelesaian sengketa, baik di pengadilan internasional maupun tribunal. ${ }^{26}$ Prinsip rule of law melindungi right to access to justice yang diberikan oleh institusi penyelesaian sengketa yang tidak memihak dan independen. Sejumlah pengadilan internasional dan tribunal seperti, International Court of Justice (ICJ), International Tribunal for the Law of the Sea (ITLoS), dan WTO, panel serta AB menawarkan akses penyelesaian sengketa dengan negara sebagai pihak dalam sengketa. Meskipun dalam praktiknya demikian, hingga saat ini belum ada ketentuan hukum internasional yang secara eksplisit dan spesifik mengatur mengenai right to access to justice bagi negara. Dalam konteks ICJ, Negara memiliki hak untuk membawa sengketa ke ICJ sebagaimana diatur dalam Article 34 para. 1 dan Article 35 para. 1 Statute of the International Court of Justice.

\section{Pengaturan dan Pemenuhan Right to Access to Justice dalam WTO}

Sistem penyelesaian sengketa perdagangan tidak dapat disebut sebagai sistem yang efektif jika sebagian besar negara anggota WTO tidak mempunyai

${ }^{23}$ Reem Bahdi, Background Paper on Women's Access to Justice in the MENA Region for International Development Research Centre (IDRC) Women's Rights and Citizenship (WRC) Program and the Middle East Regional Office (MERO) Middle East and North African (MENA) Regional Consultation December $9^{\text {th }}-11^{\text {th }} 2007$, Cairo, Egypt".[3]. https://www.uwindsor.ca/law/ rbahdi/sites/uwindsor.ca.law.rbahdi/files/womens_access_to_justice_in_mena-bahdi_en.pdf.

${ }^{24}$ ibid.[28]-[29].

${ }^{25}$ ibid.[3].

${ }^{26}$ Robert O. Keohane, Andrew Moravesik, dan Anne-Marie Slaughter, Op.Cit.[457]. 
akses yang praktis terhadap sistem tersebut. ${ }^{27}$ Akses diperlukan agar negara anggota WTO dapat berpartisipasi dalam proses penyelesaian sengketa. Partisipasi sangat penting untuk membentuk penafsiran dan penerapan hukum WTO dari waktu ke waktu. ${ }^{28}$

Salah satu fungsi penting WTO adalah berkaitan dengan ketentuan mengenai keterjangkauan dan akses yang setara. Tujuannya untuk mendukung negara yang lemah (developing countries dan least-developed countries). Meskipun negara berkembang bukanlah actor utama penggua sistem penyelesaian sengketa WTO, tetapi keberadaan hak untuk mengakses penyelesaian sengketa (right to access to justice) tetap menjadi hak yang penting dan mendasar. Dalam DSU sendiri tidak ada ketentuan yang secara eksplisit mengatur mengenai right to access to justice bagi negara anggota WTO. Namun, DSU menghormati dan secara khusus membahas mengenai access to justice bagi negara berkembang secara implisit melalui pemberian perlakuan khusus dan berbeda (special and differential treatment atau SDT) dalam bentuk hak prosedural khusus. ${ }^{29}$

Menurut David Mc Rae, terdapat empat karakteristik dari DSU yang dapat membantu negara-negara anggota WTO untuk memperoleh access to justice dalam perdagangan internasional. Pertama yaitu jangka waktu penyelesaian sengketa yang ketat dan putusan mengikat yang dihasilkan karena negatif atau reverse consensus berdasarkan Article 16.4 dan Article 17.4 DSU. Kedua yakni interpretasi yang didasarkan pada Article 31 Vienna Convention on Law of the Treaties (VCLT). Hal ini membantu negara anggota yang bersengketa untuk memahami bagaimana kewajiban yang tercantum dalam perjanjian-perjanjian WTO dan ketentuan DSU berlaku, sehingga meningkatkan prediktabilitas. Ketiga yaitu keberadaan prinsip-prinsip penafsiran yang jelas dan 'extensive body of jurisprudence' yang

${ }^{27}$ Donald McRae, 'Measuring the Effectiveness of the WTO Dispute Settlement System', (2008) 2 Asian Journal of WTO and International Health Law and Policy.[16].

${ }^{28}$ Gregory Shaffer, 'How to Make the WTO Dispute Settlement System Work for Developing Countries: Some Proactive Developing Country Strategies' (2003) 5 ICTSD Resource Paper.[10].

${ }^{29}$ Gbenga Oduntan, 'Access to justice in international courts for indigent states, persons and peoples’ (2018) 58 Indian Journal of International Law.[294]. 
menghasilkan transparansi dan konsistensi. Keempat yakni catatan pemenuhan atau kepatuhan yang menunjukkan kecakapan serta popularitas dari DSU WTO. ${ }^{30}$

Sebagai bagian dari sistem penyelesaian sengketa WTO, keberadaan AB juga untuk memenuhi right to access to justice dalam WTO. Tingginya angka banding atau persentase yang relatif tinggi dari negara anggota WTO yang telah terlibat dalam peninjauan banding merupakan faktor yang menaikkan keunggulan $A B{ }^{31}$ Tanpa tingkat aktivitas tersebut, $\mathrm{AB}$ jelas tidak akan mampu berkontribusi untuk pengembangan hukum perdagangan internasional. ${ }^{32}$ Pertumbuhan yang dialami oleh AB menunjukkan bahwa negara anggota WTO telah menggunakan right to access to justice yang dimilikinya dengan baik.

\section{Pemblokiran Penunjukkan Anggota AB oleh Amerika Serikat}

Berbagai kritik terkait permasalahan substantif dan prosedural dalam sistem penyelesaian sengketa WTO, khususnya yang menyangkut AB, telah disampaikan Amerika Serikat dalam pertemuan-pertemuan DSB sejak lama. Rangkaian tindakan pemblokiran yang dilakukan Amerika Serikat dimulai pada Mei 2016 yakni terhadap proses penunjukkan kembali Seung Wha Chang (Korea Selatan). Namun, kekosongan yang terjadi pada dua kursi anggota $\mathrm{AB}$ pada saat itu kemudian diatasi dengan dilakukannya penunjukkan anggota $\mathrm{AB}$ yang baru yakni Hong Zhao dan Kim Hyun Chong pada November 2016. ${ }^{33}$ Selanjutnya terjadi pada saat periode kedua dari dua anggota AB yakni Ricardo Ramirez Hernandez (Meksiko) dan Peter van den Bossche (Belgia) segera berakhir. Terjadi perbedaan pendapat mengenai prosedur penggantian keduanya. Pada akhirnya, tidak ada konsensus yang dapat dicapai untuk memulai proses penunjukkan anggota $\mathrm{AB}$ guna menggantikan

${ }^{30}$ Yasir Altaf, Access to Justice in International Trade with Particular Focus on Developing \& Least Developed Members in WTO (Thesis University of Iceland 2018). [41]. dikutip dari David Mc Rae, 'What is the Future of WTO Dispute Settlement?' (2004) 7 Journal of International Economic Law.[3]-[5].

${ }^{31}$ Peter Van den Bossche, 'From Afterthought to Centerpiece: The WTO Appellate Body and its Rise to Prominence in the World Trading System', (2005) 1 Maastricht Faculty of Law Working Paper. [22]-[23]

32 ibid.[27].

${ }^{33}$ Minutes of the DSB Meeting pada 23 November 2016 (WT/DSB/M/389),[13.3]. 
Ramirez maupun van den Bossche hingga periode keduanya berakhir. ${ }^{34}$ Akibatnya tiga dari tujuh posisi anggota $\mathrm{AB}$ menjadi kosong.

Pemblokiran selanjutnya terjadi pada Shree Baboo Chekitan Servansing yang periode pertamanya berakhir pada 30 September $2018 .{ }^{35}$ Di dalam the President's 2018 Trade Policy Agenda, Amerika Serikat menganggap bahwa laporan AB telah jauh melampuai ketentuan yang tercantum dalam perjanjian WTO. ${ }^{36}$ Amerika Serikat menggunakan hal tersebut sebagai alasan untuk terus melakukan pemblokiran. Dengan demikian, anggota $\mathrm{AB}$ yang tersisa hanya tiga orang. Pada 10 Desember 2019, periode kedua dari dua anggota AB yang tersisa yakni Ujal Singh Bhatia (India) dan Thomas R. Graham (Amerika Serikat) telah selesai. Dengan berakhirnya masa kerja kedua anggota $\mathrm{AB}$ tersebut, maka $\mathrm{AB}$ hanya menyisakan satu anggota yakni Hong Zhao (China) yang masa kerja periode pertamanya akan berakhir pada tanggal 30 November 2020.

Beberapa isu utama yang mendasari tindakan pemblokiran yang dilakukan oleh Amerika Serikat. Pertama, terkait ketidakpatuhan AB terhadap batas waktu banding. Pada prinsipnya proses peninjauan banding AB tunduk pada batas waktu yang ketat sebagaimana diatur dalam Article 17 para. 5 DSU. Namun, beberapa tahun terakhir $\mathrm{AB}$ telah melanggar batas waktu tersebut dan tanpa adanya kesepakatan dari para pihak dalam sengketa. ${ }^{37}$ Kedua, terkait penggunaan Rule 15 Working Procedures. Amerika Serikat berpendapat bahwa AB tidak memiliki kewenangan untuk menganggap seseorang yang bukan anggota $\mathrm{AB}$ sebagai anggota AB. Isu ketiga, terkait permasalahan substansi dalam laporan AB. Amerika Serikat menemukan adanya penggunaan obiter dicta atau advisory opinion terhadap isu yang tidak diperlukan dalam beberapa laporan AB. Sebagai contoh dalam sengketa China - Publications and Audiovisual Products, Argentina - Financial Services

\footnotetext{
${ }^{34}$ Jens Lehne, 'Crisis at the WTO: Is the Blocking of Appointments to the WTO Appellate Body by the United States Legally Justified?'. 6. [14]. dalam Daniel Hurlimann dan Marc Thommen (eds), sui generis, (Carl Grossmann Publishers 2019).

${ }^{35}$ Lihat Minutes of the DSB Meeting pada 27 Agustus 2018 (WT/DSB/M/417), para. [12.1].

36 ibid.[12.2].

${ }^{37}$ Minutes of the DSB Meeting pada 5 Oktober, 2011 (WT/DSB/M/304).[4].
} 
dan EU - PET (Pakistan). ${ }^{38}$ Selain itu juga adanya peninjauan fakta dan hukum domestik negara anggota WTO seperti dalam laporan sengketa $U S$ - Countervailing and Anti-Dumping Measures (China). ${ }^{39}$ Amerika juga mengangkat isu mengenai perlakuan terhadap laporan $\mathrm{AB}$ sebagai preseden serta adanya penambahan dan pengurangan hak dan kewajiban negara anggota WTO dalam laporan AB yang bertentangan dengan Article 3 para. 2 DSU.

\section{Akibat Pemblokiran Penunjukkan Anggota AB terhadap Pemenuhan Right to Access to Justice dalam WTO}

Pemblokiran yang dilakukan oleh Amerika Serikat terhadap proses penunjukkan dan penunjukkan kembali anggota $\mathrm{AB}$ menyebabkan terjadinya kekosongan dalam tubuh AB. Setelah tanggal 10 Desember 2019, AB hanya memiliki satu anggota, sehingga tidak dapat melakukan peninjauan banding, baik terhadap beberapa laporan panel yang diajukan sebelum tanggal tersebut maupun yang baru diajukan setelahnya. Meskipun AB tidak dapat beroperasi bukan berarti bahwa peninjauan banding dilarang. ${ }^{40}$ Negara-negara anggota WTO tetap dapat mengajukan peninjauan banding ke AB sebagaimana diatur dalam Article 16.4 DSU. Namun, demikian AB tidak dapat melakukan proses peninjauan banding dan memutuskan untuk menangguhkan semua proses banding.

Salah satu tolak ukur pemenuhan right to access to justice berdasarkan aspek prosedural dalam access to justice berkaitan dengan institusi penyelesaian sengketa. Suatu institusi tidak hanya harus ada atau tersedia, tetapi juga harus berfungsi sesuai dengan kewenangannya agar dapat menyediakan access to justice. Dengan kondisi AB saat ini, institusi tersebut memang ada atau tersedia, tetapi tidak dapat berfungsi karena jumlah anggota tidak memenuhi ketentuan kuorum divisi dalam DSU.

\footnotetext{
${ }^{38}$ Lihat Jens Lehne, Op.cit.[51-54].

39 Henry S. Gao, 'Disruptive construction or constructive destruction? Reflections on the Appellate Body crisis' (2020) 1 Reasearch Collection Scholl Of Law Singapore Management University.[2].

40 Geraldo Vidigal, 'Living without the Appellate Body: Hegemonic, Fragmented and Network Authority In International Trade’ (2019) 15 Amsterdam Law School Legal Studies Research Paper.[21].
} 
Ketidakmampuan $\mathrm{AB}$ dalam melakukan peninjauan banding mengakibatkan laporan panel yang telah diajukan banding akan mengalami 'limbo' (paling tidak sampai adanya penunjukkan anggota $\mathrm{AB}$ baru) dan tidak dapat diadopsi oleh DSB (kecuali, mungkin, dengan positive consensus). ${ }^{41}$ Laporan yang tidak diadopsi oleh DSB tidak akan menghasilkan dampak hukum seperti memicu kewajiban untuk implementasi, mengajukan periode waktu yang wajar terkait proses kepatuhan, atau mengizinkan adopsi dari tindakan balasan jika terjadi ketidakpatuhan. ${ }^{42}$

Sebagai contoh adalah sengketa Thailand - Customs and Fiscal Measures on Cigarettes from the Philippines. Filipina meminta otorisasi dari DSB untuk melakukan tindakan balasan dengan menangguhkan penerapan konsesi atau kewajiban lainnya berdasarkan perjanjian-perjanjian WTO terhadap Thailand. Namun, Thailand berpendapat bahwa tindakan tersebut tidak benar karena dilakukan disaat proses banding sedang berlangsung, sehingga belum ada laporan yang diadopsi oleh yang harus dipatuhi. ${ }^{43}$

Dalam sengketa tersebut, Filipina kehilangan hak pemulihannya karena tidak dapat memperoleh otorisasi dari WTO (DSB) untuk melakukan tindakan balasan kepada Thailand. Kegagalan dalam menyelesaikan permasalahan yang terjadi pada $\mathrm{AB}$ memungkinkan negara pihak dalam sengketa (yang dalam sengketa di atas adalah Filipina) untuk bertindak secara sepihak dan menggunakan retaliasi untuk mendapatkan keinginannya. ${ }^{44}$ Daripada menggunakan 'court' untuk memutuskan jumlah retaliasi yang sesuai, negara seperti Filipina akan melakukan dengan cara mereka sendiri. Selain itu, dari posisi Thailand, dalam kurun waktu yang tidak terbatas, Thailand tidak dapat mengakses haknya untuk mendapatkan tinjauan banding dari AB atas sengketa

\footnotetext{
${ }^{41}$ Joost Pauwelyn, 'WTO Dispute Settlement Post 2019: What to Expect?' (2019) 22 Journal of International Economic Law.[310].

${ }^{42}$ Geraldo Vidigal, Loc.cit.

43 Thailand-Customs And Fiscal Measures on Cigarettes from the Philippines Recourse to Article 22.2 of the DSU by the Philippines Communication from Thailand, WT/DS371/36, (11 Maret 2020).[15-17].

${ }^{44}$ Tetyana Payosova, Gary Clyde Hufbauer, and Jeffrey J. Schott, 'The Dispute Settlement Crisis in the World Trade Organization: Causes and Cures' (2018) Peterson Institute For International Economics.[1].
} 
tersebut. Baik Thailand maupun Filipina akan kehilangan hak-hak hukumnya yang tercantum dalam perjanjian-perjanjian WTO karena proses banding yang tidak segera terselesaikan. Ketiadaan $\mathrm{AB}$ dalam sistem penyelesaian sengketa WTO secara nyata telah menciderai pemenuhan right to access to justice negaranegara anggota WTO dan menyebabkan sejumlah kerugian dalam hal keamanan dan prediktablitas perdagangan internasional.

\section{Upaya Negara-Negara Anggota WTO dalam Menangani Pemblokiran Penunjukkan Anggota AB}

Banyak negara anggota WTO yang berinisiatif untuk mengajukan proposal guna mengatasi permasalahan yang terjadi pada AB. Salah satu proposal yang kemudian ditindaklanjuti adalah proposal yang diajukan oleh EU pada Mei 2019. Proposal tersebut mengusulkan tentang 'interim appeal arbitration berdasarkan Article 25 DSU'. EU dan sekitar 20 negara anggota WTO lainnya menyetujui pengaturan yang disebut dengan Multiparty Interim Appeal Arbitration Arrangement (selanjutnya disebut MPIA). Namun, upaya tersebut hanya bersifat sementara (shortterm) dan tetap diperlukan upaya lain untuk menangani pemblokiran penunjukkan anggota $\mathrm{AB}$ yang dilakukan oleh Amerika Serikat.

\section{Kesimpulan}

Keberadaan $\mathrm{AB}$ sebagai mekanisme peninjauan banding dalam sistem penyelesaian sengketa WTO telah menjamin dan memperkuat konsistensi serta kepastian terhadap penafsiran aturan perdagangan internasional. Dalam WTO belum ada ketentuan yang secara eksplisit mengatur mengenai right to access to justice bagi negara-negara anggota WTO. Namun, negara sebagai subyek hukum internasional mempunyai hak untuk menyelesaikan sengketa secara internasional, termasuk ke WTO. Sebagai bagian dari sistem penyelesaian sengketa WTO, AB turut berperan dalam pemenuhan right to access to justice bagi negara anggota WTO. Tingginya pengajuan peninjauan banding oleh negara-negara anggota WTO menunjukkan tingginya pemanfaatan right to access to justice. 
Pemblokiran penunjukkan dan penunjukkan kembali anggota $\mathrm{AB}$ yang dilakukan oleh Amerika Serikat telah mengakibatkan AB tidak dapat melakukan peninjauan banding. Meskipun AB tidak dapat beroperasi bukan berarti peninjauan banding dilarang. Negara tetap dapat mengajukan banding. Institusi penyelesaian sengketa harus dapat berfungsi agar mampu memenuhi right to access to justice. Dengan kondisi AB saat ini, institusi tersebut ada, tetapi tidak dapat berfungsi. Hal tersebut mengakibatkan laporan panel mengalami limbo dan memungkinkan negara pihak dalam sengketa untuk melakukan tindakan sepihak menggunakan retaliasi. Negara pihak dalam sengketa akan kehilangan hak-hak hukumnya menurut perjanjian-perjanjian WTO karena proses banding yang tidak segera terselesaikan. Tindakan pemblokiran pada AB yang dilakukan oleh Amerika Serikat secara nyata telah menciderai pemenuhan right to access to justice negara-negara anggota WTO. Negara-negara anggota WTO berupaya untuk menangani permasalahan yang terjadi pada AB. Salah satunya dengan membentuk Multiparty Interim Appeal Arbitration Arrangement (selanjutnya disebut MPIA). Upaya tersebut hanya bersifat sementara dan tetap diperlukan upaya lanjutan.

\section{Daftar Bacaan}

\section{Buku}

David Palmeter dan Petros C. Mavroidis, Dispute Settlement in the World Trade Organization: Practice and Procedure (Springer Science+Business Media Dordrecht 1999).

Francesco Francioni (ed), Access to Justice as a Human Right (Oxford University Press 2007).

Lukasz Gruszczynski dan Wouter Werner (ed), Deference in International Courts and Tribunals: Standard of Review and Margin of Appreciation (Oxford University Press 2014).

Peter Mahmud Marzuki, Penelitian Hukum (Cetakan VI Kencana 2010).

United States Committee on the Judiciary Subcommittee on Courts, Civil Liberties, and the Administration of Justice, State of the Judiciary and Access to Justice Hearings before the Subcommittee on Courts, Civil Liberties, and 
the Administration of Justice of the Committee on the Judiciary House of Representatives Ninety-Fifth Congress (U.S. Government Printing Office 1977).

\section{Kontribusi pada Buku}

Debra P. Steger, 'The Appellate Body and its contribution to WTO Dispute Settlement', dalam D. L. M. Kennedy \& J. D. Southwick (ed), The Political Economy of International Trade Law: Essays in Honor of Robert E. Hudec (Cambridge University Press 2002).

Jens Lehne, 'Crisis at the WTO: Is the Blocking of Appointments to the WTO Appellate Body by the United States Legally Justified?'. dalam Daniel Hurlimann dan Marc Thommen (eds), sui generis, (Carl Grossmann Publishers 2019).

\section{Jurnal}

Alberto do Amaral Junior, Luciana Maria de Oliveira Sa Pires, dan Cristiane Lucena Carneiro (eds), The WTO Dispute Settlement Mechanism: A Developing Country Perspective, (Springer Nature Switzerland 2019).

Donald McRae, 'Measuring the Effectiveness of the WTO Dispute Settlement System', (2008) 2 Asian Journal of WTO and International Health Law and Policy.

Gbenga Oduntan, 'Access to justice in international courts for indigent states, persons and peoples' (2018) 58 Indian Journal of International Law.

Geraldo Vidigal, 'Living without the Appellate Body: Hegemonic, Fragmented and Network Authority In International Trade’ (2019) 15 Amsterdam Law School Legal Studies Research Paper.

Gregory Shaffer, 'How to Make the WTO Dispute Settlement System Work for Developing Countries: Some Proactive Developing Country Strategies' (2003) 5 ICTSD Resource Paper.

Henry S. Gao, 'Disruptive construction or constructive destruction? Reflections on the Appellate Body crisis' (2020) 1 Reasearch Collection Scholl Of Law Singapore Management University.

Inez Lopes, 'Dispute Settlement Body of The WTO: Access to Developing Countries?' (2014). 1 Journal of the Graduate Program in Law of University of Brasilia. 
Joost Pauwelyn, 'WTO Dispute Settlement Post 2019: What to Expect?' (2019) 22 Journal of International Economic Law.

Koesrianti, 'WTO Dispute Settlement Mechanism: Indonesia's Prospective in International Trading System’ (2015). 27 Mimbar Hukum.

Mauro Cappelletti dan Bryant G. Garth, 'Access to Justice: The Newest Wave in the Worldwide Movement to Make Rights Effective' (1978) 27 Buffalo Law Review.

Miao He, 'Sustainable Development through the Right to Access to Justice in Environmental Matters in China’ (2019) MDPI Journal.

Peter Van den Bossche, 'From Afterthought to Centerpiece: The WTO Appellate Body and its Rise to Prominence in the World Trading System', (2005) 1 Maastricht Faculty of Law Working Paper.

Robert O. Keohane, Andrew Moravesik, dan Anne-Marie Slaughter, 'Legalized Dispute Resolution: Interstate and Transnational' (2000) 54 International Organization.

Tetyana Payosova, Gary Clyde Hufbauer, and Jeffrey J. Schott, 'The Dispute Settlement Crisis in the World Trade Organization: Causes and Cures' (2018) Peterson Institute For International Economics.

\section{Thesis}

Yasir Altaf, Access to Justice in International Trade with Particular Focus on Developing \& Least Developed Members in WTO (University of Iceland 2018).

\section{Paper}

Reem Bahdi, Background Paper on Women's Access to Justice in the MENA Region for International Development Research Centre (IDRC) Women's Rights and Citizenship (WRC) Program and the Middle East Regional Office (MERO) Middle East and North African (MENA) Regional Consultation December $9^{\text {th }}-11^{\text {th }} 2007$, Cairo, Egypt". https://www.uwindsor.ca/law/rbahdi/sites/ uwindsor.ca.law.rbahdi/files/womens_access_to_justice_in_mena-bahdi_ en.pdf.

\section{Perjanjian Internasional}

Annex 2 Marrakesh Agreement Establishing the World Trade Organization 1994 Understanding on Rules and Procedures Governing the Settlement of Disputes 


\section{Laman}

United State International Trade Commission (USTR), 'Statement by Ambassador Robert E. Lighthizer on Retaliatory Duties' (Press Release, 26 Juni 2018) <https://ustr.gov/about-us/policy-offices/press-office/press-releases/2018/ june/statement-ambassador-robert-e $>$ accessed 26 Januari 2020.

\section{Dokumen Lain}

Minutes of the DSB Meeting pada 23 November 2016 (WT/DSB/M/389).

Minutes of the DSB Meeting pada 27 Agustus 2018 (WT/DSB/M/417).

Minutes of the DSB Meeting pada 5 Oktober 2011 (WT/DSB/M/304).

Thailand - Customs And Fiscal Measures on Cigarettes from the Philippines Recourse to Article 22.2 of the DSU by the Philippines Communication from Thailand, WT/DS371/36, (11 Maret 2020). 
Novia Dwi: Pemblokiran Penunjukkan Anggota...

--halaman ini sengaja dibiarkan kosong-- 